\title{
Impact of hybrid thoracoabdominal aortic repair on visceral and spinal cord perfusion: The new and improved SPIDER-graft
}

Sabine Wipper, MD, PhD, ${ }^{\mathrm{a}}$ Tilo Kölbel, MD, PhD, ${ }^{\mathrm{a}}$ Harleen K. Sandhu, MD, MPH, ${ }^{\mathrm{b}}$ Daniel Manzoni, MD, ${ }^{\mathrm{a}}$ Anna Duprée, MD, ${ }^{c}$ Anthony L. Estrera, MD, ${ }^{b, d}$ Hazim Safi, MD, ${ }^{b, d}$ Charles C. Miller III, PhD, ${ }^{b}$ Nikolaos Tsilimparis, $\mathrm{MD}, \mathrm{PhD},{ }^{\mathrm{a}}$ and E. Sebastian Debus, $\mathrm{MD}, \mathrm{PhD}^{\mathrm{a}}$

\section{ABSTRACT}

Objectives: SPIDER-graft for thoracoabdominal aortic aneurysm repair avoiding thoracotomy and extracorporeal circulation was modified, enabling reimplantation of lumbar arteries to prevent spinal cord ischemia and compared with open aortic repair (control) in a pig model.

Methods: Graft implantation was performed in 7 pigs per group $(75-85 \mathrm{~kg})$. For SPIDER-graft (groups I and II), the infra-diaphragmatic aorta was exposed through retroperitoneal access. The right iliac branch was first temporarily anastomosed end-to-side to the distal aorta maintaining periprocedural retrograde visceral perfusion. SPIDER-graft was deployed in the descending thoracic aorta via the celiac artery ostium. The celiac, superior mesenteric, and renal arteries were successively connected to the corresponding side branches of the graft. In group II, the lumbar arteries were reimplanted into the former access branch. For control, complete thoracoabdominal exposure of the aorta was required. After crossclamping, proximal anastomosis was performed, and the celiac artery, superior mesenteric artery, renal arteries, and iliac arteries were reattached. Technical feasibility, ischemic times, blood flow, and visceral and spinal cord perfusion in the related organs were evaluated before implantation and 3 and 6 hours after implantation using transit-time flow measurement and fluorescent microspheres.

Results: Technical success was achieved in all animals in all groups. Total aortic clamping time and selective ischemic times of related organs were significantly longer during open aortic repair compared with groups I and II $(P<.0001)$. Fluorescent microspheres confirmed best spinal cord perfusion in group II.

Conclusions: SPIDER-graft reduced ischemic time, avoided extracorporeal circulation and thoracotomy, and improved spinal cord perfusion during thoracoabdominal aortic aneurysm repair in a pig model. (J Thorac Cardiovasc Surg 2019;158:692-701)

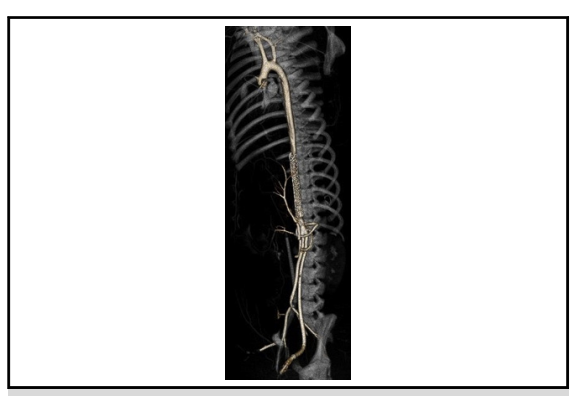

CT scan with SPIDER-graft for hybrid thoracoabdominal aortic repair after implantation.

\section{Central Message}

SPIDER-graft for thoracoabdominal aortic repair, avoiding ECC and enabling reimplantation of lumbar arteries, confirms improved spinal cord perfusion in a large animal model.

\section{Perspective}

SPIDER-graft (thoracic stent-graft connected to multi-branched Dacron graft) for hybrid repair of thoracoabdominal aortic pathologies aims to avoid ECC, to minimize ischemic time of visceral organs, and to reduce risk of SCI during thoracoabdominal aortic repair. Experimental data confirm the technical feasibility, sufficient visceral, and spinal cord perfusion.

See Commentaries on pages 702 and 704.
Although endovascular treatment options with fenestrated and branched endovascular repair is already routinely used for thoracoabdominal aortic aneurysm (TAAA)

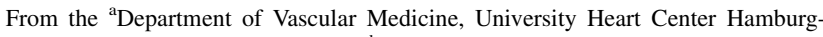
Eppendorf, Hamburg, Germany; ${ }^{\mathrm{b}}$ Department of Cardiothoracic and Vascular Surgery, McGovern Medical School, UTHealth, Houston, Tex; ${ }^{\mathrm{c}}$ Department of General and Visceral Surgery, University Hospital Hamburg-Eppendorf, Hamburg, Germany; and ${ }^{\mathrm{d}}$ Heart and Vascular Institute, Memorial Herman Hospital, Texas Medical Center, Houston, Tex.

The study was supported by the "Nicklas Braack Charity" and a research grant from Vascutek for costs of animals and the SPIDER-graft prosthesis.

Read at the 98th Annual Meeting of The American Association for Thoracic Surgery, San Diego, California, April 28-May 1, 2018. treatment in dedicated centers, open aortic repair (OAR) remains the standard of care in many centers and in patients with connective tissue disease. OAR has undergone major

Received for publication April 23, 2018; revisions received Nov 2, 2018; accepted for publication Nov 10, 2018; available ahead of print Feb 10, 2019.

Address for reprints: Sabine Wipper, MD, PhD, Department of Vascular Medicine,

University Heart Center, Universitätskrankenhaus Hamburg Eppendorf, Martinistr

52, 20246 Hamburg, Germany (E-mail: s.wipper@uke.de). $0022-5223 / \$ 36.00$

Copyright (C) 2018 by The American Association for Thoracic Surgery https://doi.org/10.1016/j.jtcvs.2018.11.133 

Abbreviations and Acronyms
$\mathrm{CA}=$ celiac artery
$\mathrm{CO}=$ cardiac output
$\mathrm{CT}=$ computed tomography
ECC = extracorporeal circulation
$\mathrm{FM}=$ fluorescent microsphere
LRA $=$ left renal artery
MAP $=$ mean arterial pressure
OAR = open aortic repair
RRA = right renal artery
SCI = spinal cord ischemia
SMA $=$ superior mesenteric artery
TAAA $=$ thoracoabdominal aortic aneurysm
TTFM $=$ transit-time flow measurement

Scanning this QR code will take you to the article title page to access supplementary information. To view the AATS Annual Meeting Webcast, see the URL next to the webcast thumbnail.

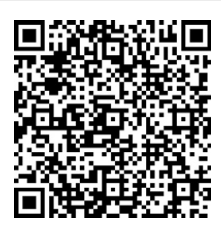

improvements over the past decades, including a multimodal access to organ protection, consisting of mild hypothermia, cerebrospinal fluid drainage, left heart bypass, sequential clamping of the aorta, and selective reimplantation of intercostal and lumbar arteries. ${ }^{1}$ Despite the decline in perioperative morbidity and mortality of elective aneurysm repair with the recent technical advances, this complex procedure remains challenging. There is still a considerable risk of severe perioperative complications, which globally has led to centralization of these highly demanding procedures..$^{2-8}$

Recently, we described technical feasibility and first clinical use of a reversed frozen elephant-trunk device in a patient with dissecting TAAA, showing the need for further modifications to the device design and technique. ${ }^{9}$ The SPIDER-graft for TAAA hybrid repair was developed to minimize operative trauma, to avoid extracorporeal circulation (ECC) with related increased perioperative risk factors, to further reduce ischemic time of visceral organs, and to reduce the risk of spinal cord ischemia (SCI). The SPIDER-graft uses a combined endovascular thoracic and open abdominal aortic approach for TAAA repair in a single-stage operation, thereby avoiding the need for thoracotomy and ECC while enabling reimplantation of visceral, renal, and lumbar arteries.

The first-generation SPIDER-graft was previously evaluated in an experimental setting, demonstrating technical feasibility. ${ }^{10}$ Further modifications to the device design were implemented to improve graft deployment, fixation and stability, de-airing, and enable reimplantation of lumbar arteries. In the current study, we compare the technical feasibility study, ischemic time, end-organ blood-flow, and perfusion including quantitative assessment of spinal cord perfusion of the second-generation SPIDER-graft to first-generation SPIDER-graft and OAR in an experimental setting.

\section{MATERIAL AND METHODS}

A total of 21 domestic pigs (randomly divided into 3 study groups with 7 pigs each, $80 \pm 5 \mathrm{~kg}$ ) were operated at the animal laboratories, University Heart Center Hamburg, Germany. The study was performed in accordance with the "Position of the American Heart Association on Research Animal Use" (Circulation, April 1985) and approved by the government animal care committee (AZ101/15) and the institutional review board for the care of animal subjects. Partial results of 6 animals operated first-generation SPIDER-graft have been reported. ${ }^{10}$

\section{Device Description}

Open aortic repair. OAR was performed using a gelatin-sealed polyester tube graft (Gelsoft, Vascutec, Glasgow, Ireland) $20 \mathrm{~mm}$ in diameter connected to a bifurcated graft $(6-\mathrm{mm}$ diameter for both iliac branches). Four branches (6 mm each) were integrated into the main body for reimplantation of celiac artery (CA), superior mesenteric artery (SMA), left renal artery (LRA), right renal artery (RRA), and left and right iliac arteries (Figure 1, A).

Spider-graft. The SPIDER-graft (Figure 1, B) was previously described and is adjusted to the aortic diameters of an $80-\mathrm{kg}$ pig, evaluated in a postmortem computed tomography (CT) angiography. ${ }^{10}$ The first-generation SPIDER-graft consists of a proximal stent-graft (24-mm diameter, 150-mm length) with ring stent technology equipped with 4 pairs of hooks at the proximal landing zone connected to a distal gelatin-sealed polyester 6-branched graft (6 mm each) for reimplantation of visceral and iliac arteries. All side branches, except the proximal 1 for CA, are distally closed by suture. A 10-mm access branch is included in the main body to accommodate the delivery system for the proximal stent-graft. A Siena collar between both components enables suture fixation of the thoracic part in the native aortic vessel. The device is loaded into a $30 \mathrm{~F}$ peel-away sheath. The handle with the delivery system is inserted via the 10-mm access branch and fixed with a splitter. The release wire for fixation of the proximal stent-graft component on the introducer tip is inserted through the delivery system and fixed on a release clip at the end of the handle.

Second-generation SPIDER graft (Figure 1,C) was modified as follows: The nose cone was modified to enable easier graft insertion into the aorta. The longitudinal stiffness and stability of the stent-graft were increased by modification of the ring stent orientation and anatomy to improve stent-graft fixation and to avoid stent-graft migration. A $10-\mathrm{mm}$ introducer branch was positioned on the dorsal side with a length of to $200 \mathrm{~mm}$ to enable reimplantation of lumbar arteries after graft deployment.

\section{Graft Implantation}

Control group: Open aortic repair. The thoracoabdominal aorta, CA, SMA, LRA, and both iliac arteries were exposed via retroperitoneal access. The diaphragm was dissected to enable optimal exposure of the thoracic aorta.

The thoracic aorta was crossclamped and dissected, and proximal anastomosis was performed in end-to-end fashion. Cardiac output (CO) was reduced by in-flow reduction using manual compression of the inferior 

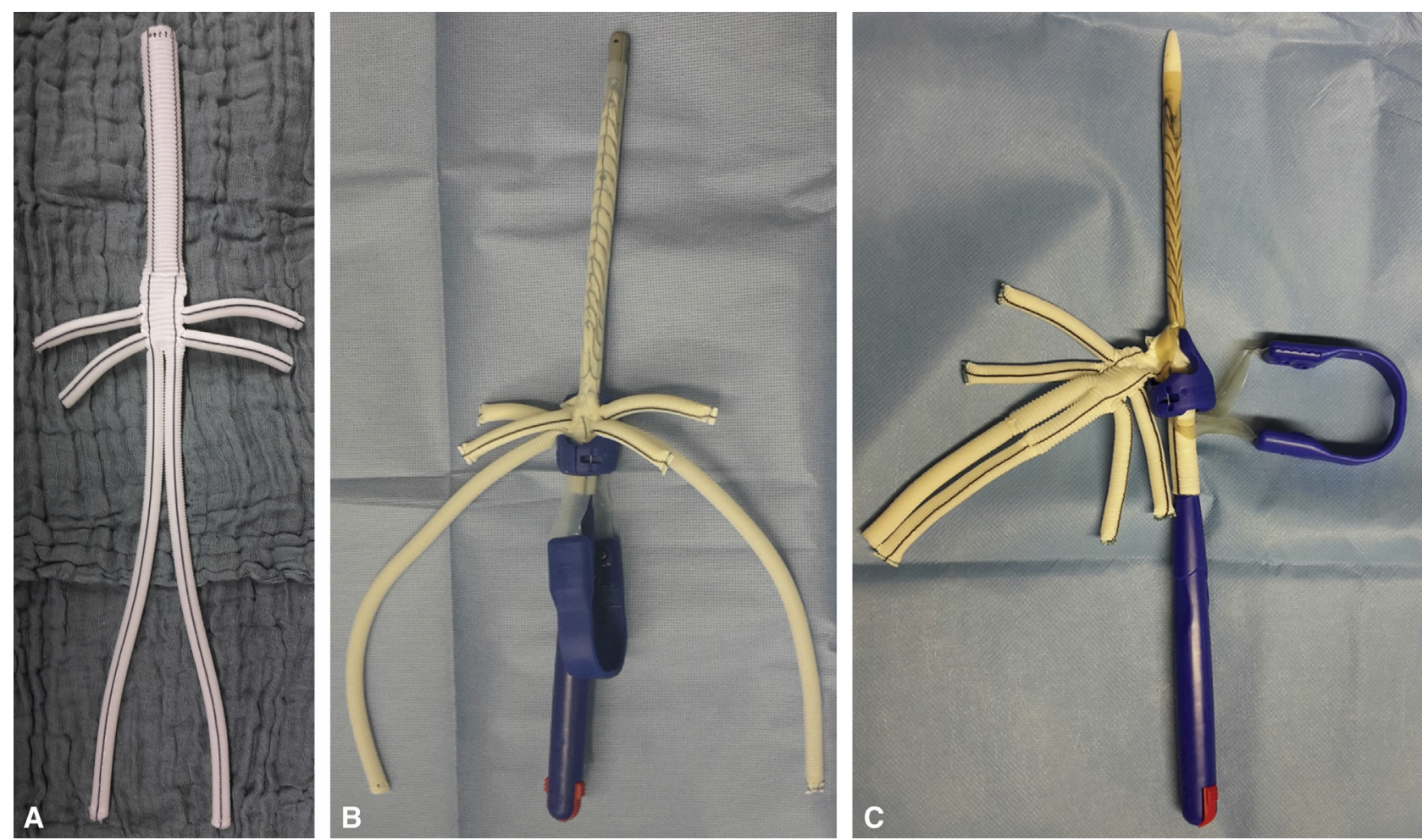

FIGURE 1. A, Conventional 20-mm 4-branched (6 mm each) gelatin-sealed bifurcated polyester for control group. B, First-generation SPIDER-graft with ring-shaped stent-graft $(24 \mathrm{~mm})$ and a 6-arm Dacron Gelsoft graft $(6 \mathrm{~mm}$ each). Splitter with peel away sheath between both components and handle with release-wire for proximal graft fixation through 10-mm access branch. C, Second-generation SPIDER-graft with modified nose cone and long dorsal sidebranch.

vena until CA anastomosis was performed and CA was reperfused to avoid elevated blood pressure peaks and right heart failure during crossclamping. After de-airing, stepwise visceral and renal artery reattachment was performed in end-to-end fashion starting with the CA, followed by SMA, RRA (from inside after opening the aorta), and LRA. Therefore, the abdominal aorta was crossclamped subsequently. Intercostal and lumbar arteries were occluded by suture. Finally, both iliac arteries were reattached.

SPIDER-graft (groups I and II). Detailed SPIDER-graft implantation technique was previously described. ${ }^{10}$ Abdominal aorta including CA, SMA, LRA, and both iliac arteries were exposed via a retroperitoneal approach. The right iliac branch was first temporarily anastomosed end-to-side to the distal aorta or common iliac artery and clamped until the implantation of the stent-graft was completed. After infraceliac crossclamping, the CA was divided and the SPIDER-graft was introduced into the descending aorta via the $\mathrm{CA}$ ostium while $\mathrm{CO}$ was reduced by in-flow reduction using manual compression of the inferior vena. The device was positioned with the collar just outside the vessel wall. The peel-away sheath was retracted, the proximal fixation was released, the splitter was removed, and the handle was carefully extracted via the side access branch.

After the deployment of the SPIDER-graft, in-flow reduction was released, and the graft was de-aired via the access branch. Then, retrograde distal perfusion via the previously attached iliac side branch was established.

Thereafter, stepwise visceral and renal arteries were reattached in end-to-end fashion starting with the CA, followed by SMA, RRA (from inside after opening the aorta), and LRA. In group II, using second-generation SPIDER-graft, lumbar arteries were reimplanted as a patch into the previous 10-mm access branch. which was used as loop-graft. The distal part of the branch was reanastomosed to the left iliac sidebranch. The initial temporizing aortic anastomosis was replaced by end-to-end anastomosis to both iliac arteries (Video 1).

\section{Anesthesia and Instrumentation}

After intramuscular premedication with azaperone $(4 \mathrm{mg} / \mathrm{kg})$, midazolam $(0.3 \mathrm{mg} / \mathrm{kg})$, ketamine hydrochloride $(5 \mathrm{mg} / \mathrm{kg})$, and atropine sulfate $(0.15 \mathrm{mg} / \mathrm{kg})$, intravenous anesthesia was induced by pentobarbital $(8 \mathrm{mg} / \mathrm{kg})$ and maintained by fentanyl $(0.01 \mathrm{mg} / \mathrm{kg} / \mathrm{h})$, midazolam $(0.1 \mathrm{mg} / \mathrm{kg} / \mathrm{h})$, and ketamine hydrochloride $(0.06 \mathrm{mg} / \mathrm{kg} / \mathrm{h})$.

Pigs were endotracheally intubated and pressure-controlled ventilated at $15 \mathrm{~cm} \mathrm{H}_{2} \mathrm{O}$ with a PEEP of $7 \mathrm{~cm} \mathrm{H}_{2} \mathrm{O}$ at 16 breaths per minute using $30 \%$ oxygen. Activated clotting time of at least 300 seconds was achieved by heparin $(400 \mathrm{IU} / \mathrm{kg})$. A $6 \mathrm{~F}$ sheath in the right carotid artery monitored mean arterial pressure (MAP) and enabled arterial blood-gas analyses. A Swan-Ganz catheter (Pulsion, Munich, Germany) was inserted via the right jugular vein for monitoring of central venous pressure, pulmonary arterial pressure, and left atrial pressure. The Swan-Ganz catheter was zeroed to ambient air pressure to calibrate before each measurement. A $5 \mathrm{~F}$ PiCCO-catheter (Pulse Contour Cardiac Output; Pulsion Medical Systems, Munich, Germany) was inserted in the left common femoral artery to monitor $\mathrm{CO}$, systemic vascular resistance, and distal MAP. The PiCCO catheter was calibrated at the beginning of each experiment using thermodilution with $20 \mathrm{~mL}$ of $\mathrm{NaCl}$ at $8^{\circ} \mathrm{C}$ (mean value of 3 consecutive injections). For quantitative assessment of organ perfusion using fluorescent microspheres (FMs), a 7F sheath was inserted into the right common femoral artery to insert a $5 \mathrm{~F}$ pigtail catheter into the descending thoracic aorta for retraction of reference blood. After median sternotomy, a left $5 \mathrm{~F}$ catheter was introduced into the left atrium for injection of FM. 


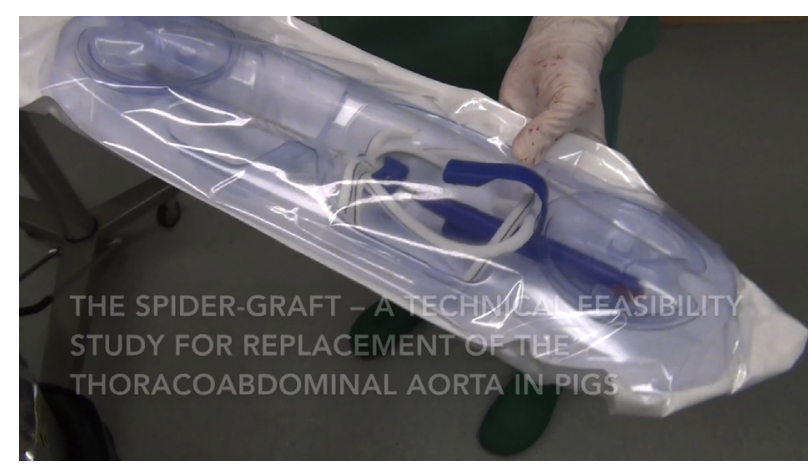

VIDEO 1. Steps of SPIDER-graft deployment: 1 . Retroperitoneal exposure of abdominal aorta. 2. End-to-side anastomosis of iliac side-branch of the SPIDER graft to distal aorta for later retrograde visceral perfusion. 3. Infraceliac crossclamping, dissection of CA, introduction of SPIDER-graft through CA ostium to descending thoracic aorta with collar just outside the aorta. 4. Retraction of peel-away sheath, removal of splitter, release of proximal fixation, extraction of handle via side access branch, clamping of access branch. 5. De-clamping for retrograde visceral perfusion via the previously attached iliac side branch. 6 . Stepwise reattachment of visceral and iliac arteries. Video available at: https://www.jtcvs.org/article/S00225223(18)33309-9/fulltext.

In groups I and II, the sternotomy was closed by clamps during graft deployment, and in all groups, the sternum was closed during follow-up measurement timings.

All hemodynamic and respiratory parameters were continuously monitored and recorded according to a standardized protocol during each intervention. Isotonic and colloidal solutions were continuously infused to achieve a stable global end-diastolic volume.

After retroperitoneal exposure of the abdominal aorta, visceral and renal arteries and both iliac arteries were dissected free from surrounding tissue to place a 6-mm flow-measurement probe (Cardiomed, Medistim AS, Oslo, Norway) to monitor the blood-flow during measurements by transit-time flow measurement (TTFM) technique.

\section{Experimental Protocol and Hemodynamic Measurements}

Graft implantation was performed by 2 senior vascular surgeons with high experience in open aortic surgery. Three study groups were evaluated: In the control-group (OAR), thoracolaparotomy was performed and a 20-mm bifurcated graft with 4 side branches for visceral and renal arteries was implanted $(n=7)$. In group I, first-generation SPIDER-graft was implanted $(\mathrm{n}=7)$, and in group II second-generation SPIDER-graft with reimplantation of lumbar arteries was used $(n=7)$.

Hemodynamic parameters were continuously monitored and recorded during each intervention. For each animal, full hemodynamic measurements including arterial and venous blood-gas analyses, and TTFM were acquired both before (baseline) and after implantation of the prosthesis with anastomosis of all side branches and hourly during an observation time of 6 hours. Angiographies were performed directly after the implantation of the graft (T1) and 6 hours thereafter (T2). Quantitative assessment of liver, kidney, bowel, and spinal cord perfusion using FMs was performed during baseline, after implantation (T1), and after 6 hours (T2).

At the end of the experiments, the pigs were killed by intravenous injection of T61 under deep anesthesia, and the SPIDER-grafts were explanted for photo-documentation. One representative animal in each group was subjected to postmortem CT angiography using a $12 \mathrm{~F}$ sheath in the distal aorta and the inferior vena cava for postoperative graft control.
One lobe of the liver, both kidneys, $30 \mathrm{~cm}$ bowel, and spinal cord were harvested and preserved in $4 \%$ formalin for FM assessment.

\section{Fluorescent Microspheres}

FM, $15 \mu \mathrm{m}$ in diameter (Molecular Probes, Eugene, Ore), as the gold standard for regional perfusion measurement in experimental large animal studies, were injected into the left atrium during withdrawal of a reference blood sample via the descending thoracic aorta, as previously described. ${ }^{11-14}$ Each vial of microspheres was placed in an ultrasonic water bath for 5 to 10 minutes and vortexed twice for 3 minutes to ensure proper mixing before injection. Approximately $4 \times 10^{6} \mathrm{FM}$ were suspended in physiologic saline solution to a volume of $10 \mathrm{~mL}$ and injected constantly over 60 seconds at each intervention. Reference blood samples were withdrawn from the descending thoracic aorta through a $5 \mathrm{~F}$ pigtail catheter with a constant-rate withdrawal pump at $3.14 \mathrm{~mL} / \mathrm{min}$ over 3 minutes (model 640A, Harvard Apparatus, South Natick, Mass). At the end of the experiments, the pigs were sacrificed and 1 representative lobe of liver, both kidneys, $30 \mathrm{~cm}$ bowel, and spinal cord were harvested and fixed in $4 \%$ formaldehyde for at least 10 days.

Visceral organs were dissected into 6 tissue pieces weighing $4 \mathrm{~g}$ each. Spinal cord was dissected in total into pieces of equal size weighing between $3.5 \mathrm{~g}$ and $4 \mathrm{~g}$ each. Tissue samples and arterial blood reference were processed for determination of blood blow by spectrofluorometry according to the standard method described by Glenny and colleagues. ${ }^{15}$

\section{Statistical Analysis}

Simple statistics for continuous variables are presented as median and interquartile range (IQR). Physiologic, hemodynamic, clinical laboratory, and flow data were measured at baseline, intraprocedurally immediately after final anastomosis (T1), and at 6 hours postoperatively (T2), so statistical models were designed to account for multiple repeated measurements within subject. In addition, for microsphere-based flow data, FM distribution for each time point was assessed in at least 9 but as many as 15 separate tissue samples for each animal at each time point, so multilevel random-intercept models were used to preserve multilevel correlation structure for evaluation of the effects of graft type and time on the response variables. For the multilevel plots for spinal cord perfusion depicting spinal flow by time, model estimates were normalized to baseline and change over time was converted from $\mathrm{mL} / \mathrm{min} / \mathrm{gram}$ flow to percent change from baseline (model statistics were computed on untransformed data). All computations were performed using SAS software version 9.4 (SAS Institute, Inc, Cary, NC).

\section{RESULTS}

Graft implantation was successfully performed in all 21 pigs, and the study protocol was completed in 20 of 21 pigs. Major bleeding did not occur in any of the groups throughout preparation and implantation. Transient heart rhythm disorders during graft deployment were successfully converted by intravenous infusion of potassium and magnesium after preventive substitution of $150 \mathrm{mg}$ amiodarone before instrumentation. One pig in the control group was not included in the evaluation despite successful graft implantation because of cardiac events requiring catecholamine substitution during reperfusion, triggered by former pericarditis.

\section{Technical Feasibility}

Exposure of the descending thoracic aorta (control) and retroperitoneal exposure of the abdominal aorta, including visceral, renal, and iliac arteries (all study groups), was 

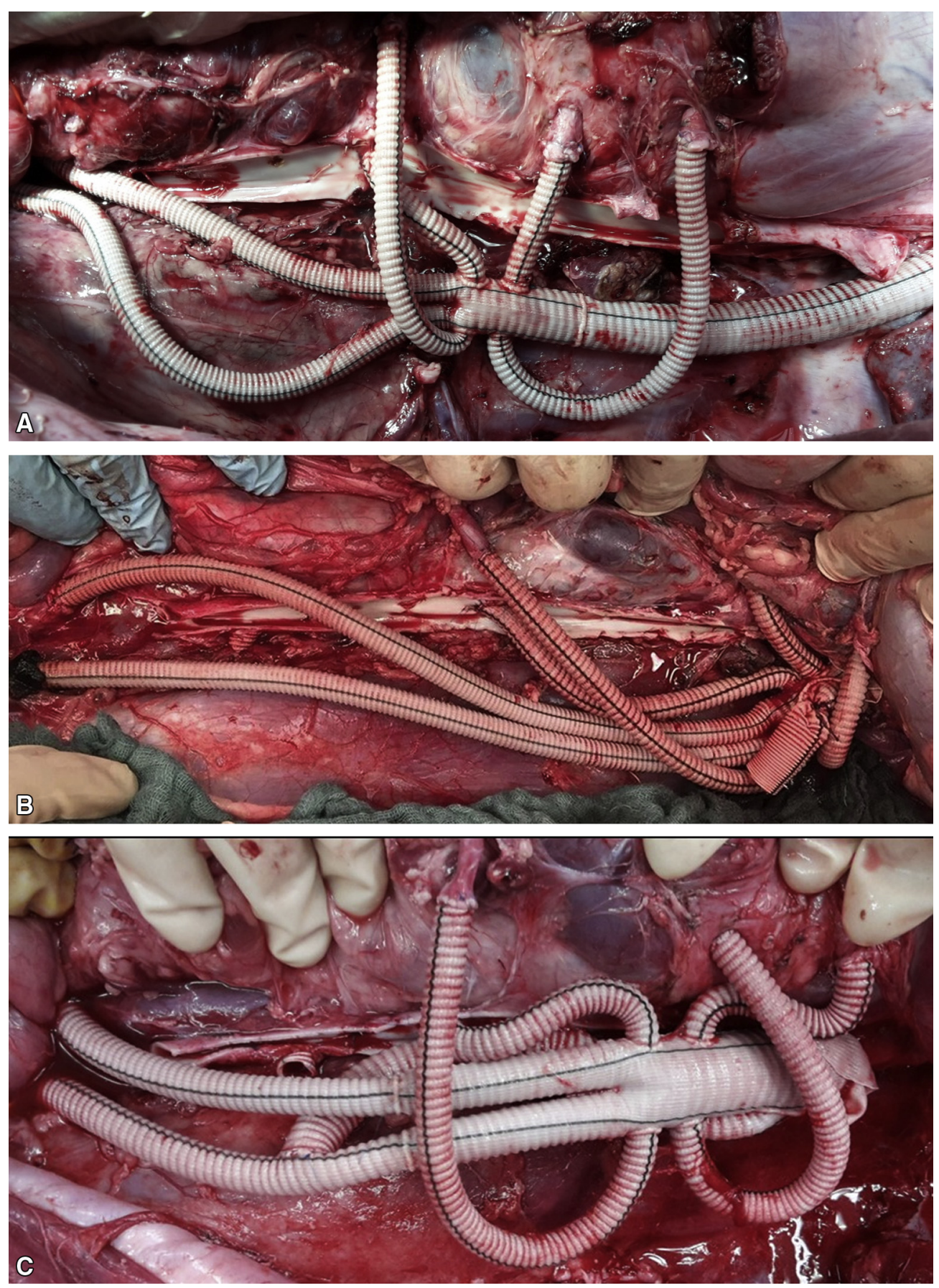

FIGURE 2. A, Representative example of thoracoabdominal aortic replacement by OAR with thoracolaparotomy and dissection of diaphragm (control-group). B, First-generation SPIDER-graft with ligated access branch (white arrow) and reattachment visceral and iliac arteries without reattachment of lumbar arteries (group I). C, Second-generation SPIDER-graft with optimized branch position and reattachment of lumbar arteries (white arrow) as loop graft (group II).

performed without significant blood loss or hemodynamic events in all animals.

In the control group, 1 pig showed cardiac events after graft implantation during reperfusion. Despite successful graft implantation, this pig was excluded from further evaluation because of perioperative catecholamine substitution. Graft implantation was successful in all remaining 6 pigs in the control group (Figure 2, A).

SPIDER-Graft deployment was successful in all animals in group I and group II (7 pigs each) (Figure 2, $B$ and $C$ ). 
Insertion of the SPIDER-graft through the CA ostium required additional extension of the $\mathrm{CA}$ access because of the rounded tip of the shaft in 5 of 7 pigs in group I, whereas the modified tip in group II required no additional incision. Likewise, extraction of the handle through the introducer branch required additional manual manipulation in all animals in group I, whereas it was technically easier and faster in group II. Stent-graft migration occurred in 2 pigs of group I without causing bleeding problems or endoleak. In group II, the proximal landing zone of the stent-graft component was properly fixed in all 7 animals, and no problems occurred during release of the handle.

Retraction of the peel-away sheath, extraction of the release wire for proximal fixation of the stent-graft, and removal of the splitter were performed without major difficulties in all animals in groups I and II. All visceral and iliac anastomoses were successfully performed in both study groups, and in addition lumbar arteries were successfully attached in group II.

Angiography and postprocedure CT scan confirmed open side branches and successful graft implantation in all animals. Implantation and ischemic times. Implantation time was the longest in the control group (177.5 minutes; 165.0-185.0) and shortest in group I (160 minutes; 105-160), but this difference was not statistically significant $(P=.0939)$. Despite additional reattachment of lumbar arteries in group II (165 minutes; 142.5-180), times were not statistically different $(P=.26)$.

Ischemic times of visceral organs were significantly longer in the control group compared with group I and group II (Table 1). Ischemic time of left kidney was added to right kidney ischemic time due to simultaneous crossclamping of both renal arteries during opening the juxtarenal aortic segment. RRA was first anastomosed from inside. During SPIDER-graft implantation, the ischemic period of the visceral organs was minimized to the time needed for the anastomosis of the respective side-branch in addition to the time required for thoracic stentgraft deployment of the SPIDER-graft.

Implantation of the SPIDER-graft, including in-flow occlusion and infra-celiac crossclamping required 4.8 minutes (4.3-5.0) in group I and 3.3 minutes (3.0-4.0) in group II, proximal anastomosis in control lasted 14.3 (13-15.3) minutes.

\section{Hemodynamic Parameters and Organ Perfusion}

Hemodynamic stability was maintained in all animals in each study group throughout the whole procedure.

During graft implantation in the control group, in-flow reduction kept MAP at baseline values until CA was anastomosed. In groups I and II, MAP was successfully decreased by $50 \%$ from baseline value during proximal stent-graft implantation of the SPIDER-graft (groups I
TABLE 1. Crossclamping times of the visceral and iliac corresponding to the ischemic times of the related organs by group median and interquartile range

\begin{tabular}{lcccc}
\hline & Control & Group I & Group II & ANOVA $\boldsymbol{P}$ \\
\hline CA & $25(24-28)$ & $11(10-14)$ & $13(12-14)$ & $<.0001$ \\
SMA & $35(33-40)$ & $8(7-10)$ & $10(9-11)$ & $<.0001$ \\
RRA & $56(54-61)$ & $13(12-18)$ & $14(10-15)$ & $<.0001$ \\
LRA & $69(64-72)$ & $25(18-26)$ & $25(22-28)$ & $<.0001$ \\
LIA & $79(76-85)$ & $10(9-16)$ & $18(14-22)$ & $<.0001$ \\
RIA & $89(87-95)$ & $10(8-12)$ & $15(10-28)$ & $<.0001$ \\
Lumbar arteries & & & $50(40-63)$ & \\
\hline
\end{tabular}

In the control group and group I, the lumbar arteries were not reimplanted. Clamping times were significantly longer in the control group compared with both SPIDER-graft groups. ANOVA, Analysis of variance; $C A$, celiac artery; $S M A$, superior mesenteric artery; $R R A$, right renal artery; $L R A$, left renal artery; $L I A$, left iliac artery; RIA, right iliac artery.

and II) until retrograde distal perfusion via the previously attached iliac side branch was established.

There was no significant blood loss as confirmed by stable hemoglobin levels. In statistical models, the main effects of hemodynamic variables, including heart rate, MAP, CO, and systemic vascular resistance, did not differ significantly between groups ( $P$ for main effect of group $P=.386, .850, .482$, and .986 , respectively).

Transit-time flow measurement. TTFM confirmed good visceral blood flow during passive shunting via iliac sidebranch without need for selective visceral perfusion and ECC: SMA: $880(550-1000) \mathrm{mL} / \mathrm{min}$ vs $800(465-1000) \mathrm{mL} / \mathrm{min}$; LRA: 145 (105-227) $\mathrm{mL} / \mathrm{min}$ vs 179 (100-290) $\mathrm{mL} / \mathrm{min}$; right iliac artery 217 (170-350) mL/min vs 264 (140-380) mL/min; group I versus group II. Because of retroperitoneal exposure of the aorta, there was no TTFM value for RRA and CA was already clamped and dissected for implantation of the SPIDER-graft via the CA ostium. TTFM flow of visceral, renal, and iliac arteries confirmed sufficient blood supply to all branches after implantation of the SPIDER-graft during 6 hours follow-up (Table 2).

Quantitative assessment of tissue perfusion. Quantitative assessment of visceral and spinal cord perfusion was successful during all measurement points in all animals. Liver, both kidneys, and bowel were dissected to analyze 6 specimens of each organ with a mean weight of $3.9 \pm 0.2 \mathrm{~g}$ each. Spinal cord was dissected into 9 to 15 samples of $3.7 \pm 0.3 \mathrm{~g}$ each, depending on the lengths and thickness of the spinal cord.

During sample processing, the reference blood sample was lost in 1 pig in control during $\mathrm{T} 1$ and $\mathrm{T} 2$ and in $1 \mathrm{pig}$ in group I during $\mathrm{T} 1$ due to technical failure during blood sample processing. Bowel perfusion could not be evaluated in 1 pig in control because of technical problems during organ digestion. All other values were included in the quantitative assessment. 
TABLE 2. Transit-time flow measurement flow of visceral, renal, and iliac arteries

\begin{tabular}{|c|c|c|c|c|}
\hline & Control & Group I & Group II & ANOVA $P$ \\
\hline \multicolumn{5}{|l|}{$\mathrm{CA}$} \\
\hline Baseline & $450(380-620)$ & $550(550-605)$ & $478(360-545)$ & .375 \\
\hline $\mathrm{T} 1$ & $500(450-600)$ & $480(385-620)$ & $545(460-615)$ & .685 \\
\hline $\mathrm{T} 2$ & $450(450-550)$ & $540(410-580)$ & $550(410-710)$ & .482 \\
\hline \multicolumn{5}{|l|}{ SMA } \\
\hline Baseline & $465(420-550)$ & $370(360-460)$ & $520(420-625)$ & .175 \\
\hline $\mathrm{T} 1$ & $950(800-1000)$ & $745(650-820)$ & $830(660-935$ & .218 \\
\hline $\mathrm{T} 2$ & $550(440-650)$ & $675(570-710)$ & $570(460-665)$ & .422 \\
\hline \multicolumn{5}{|l|}{ LRA } \\
\hline Baseline & $230(200-250)$ & $250(160-325)$ & $400(270-430)$ & .031 \\
\hline $\mathrm{T} 1$ & $175(160-190)$ & $130(80-160)$ & $165(133-200)$ & .196 \\
\hline $\mathrm{T} 2$ & $115(110-120)$ & $170(150-220)$ & $178(120-300)$ & .271 \\
\hline \multicolumn{5}{|l|}{ LIA } \\
\hline Baseline & $600(550-600)$ & $550(450-550)$ & $485(415-655)$ & .875 \\
\hline $\mathrm{T} 1$ & $510(480-550)$ & $425(360-540)$ & $425(265-545)$ & .621 \\
\hline $\mathrm{T} 2$ & $470(410-500)$ & $323(220-330)$ & $355(260-293)$ & .008 \\
\hline \multicolumn{5}{|l|}{ RIA } \\
\hline Baseline & $600(550-650)$ & $545(450-550)$ & $515(450-705)$ & .766 \\
\hline $\mathrm{T} 1$ & $490(475-510)$ & $360(110-620$ & $415(165-550$ & .494 \\
\hline $\mathrm{T} 2$ & $460(430-500)$ & $350(250-500)$ & $390(315-410)$ & .116 \\
\hline
\end{tabular}

Data are presented as median with $25 \%$ and $75 \%$ percentiles ( $\mathrm{n}=6$ for control, $\mathrm{n}=7$ for groups I and II). TTFM during baseline and 6 hours after implantation of the SPIDER graft prosthesis.Note that no flow data are given for RRA because of the retroperitoneal access to the aorta. ANOVA, Analysis of variance; $C A$, celiac artery; SMA, superior mesenteric artery; LRA, left renal artery; LIA, left iliac artery; RIA, right iliac artery.

Liver, bowel, and kidney perfusion was maintained after graft implantation in all groups. Rate of change of organ-perfusion was similar for each type of graft, that is, no treatment by time interactions were observed for change from baseline to 6 hours postimplantation.

Spinal cord perfusion decreased in control remained stable during first-generation SPIDER-graft and increased after second-generation SPIDER-graft with reattachment of lumbar arteries. In Figure 3, model estimates of spinal cord blood-flow calculated by multilevel models are illustrated as percent change from baseline. Model $P$ values were as follows: for main effect of group $P<.0001$, time point $P<.05$, and time point by group interaction $P<.0001$. Finally, representative histology of spinal cord, liver, bowel, and kidney samples did not show any signs of cell death in any of the groups.

\section{DISCUSSION}

The SPIDER-graft with proximal stent-graft attached to multi-branched Dacron prosthesis was designed to reduce operative morbidity and procedure-related complications during TAAA repair. This experimental study in healthy pigs confirms technical feasibility of hybrid thoracoabdominal aortic repair by avoiding the need of thoracotomy and ECC while reducing ischemic times and reattachment of lumbar arteries to prevent SCI by using the SPIDER-graft.

Because the SPIDER-graft allows temporary retrograde distal perfusion of visceral and renal arteries via the iliac access side-branch after the deployment of the thoracic part of the device, SPIDER-graft precludes the need for selective visceral perfusion and ECC. In this experimental study, intraoperative TTFM and quantitative assessment of liver, kidney, and bowel perfusion by FM confirmed the proof of concept of passive shunting and supported the concept of retrograde visceral perfusion via iliac side branch of the SPIDER graft.

Avoiding ECC might play a key role in improving the treatment outcomes by reducing the perioperative risk of bleeding and the need for blood products. This might be beneficial for oxygen supply to the spinal cord. Furthermore, the activation of the complement cascade and inflammatory response can be attenuated, further reducing edema formation by capillary leakage and decreasing the risk of SCI. In addition, ECC-related hypotension can be avoided.

By using the SPIDER-graft, intraoperative clamping time can be reduced significantly compared with conventional OAR. Shorter clamping time may avoid ischemia-reperfusion-related hypotension.

Reattachment of lumbar arteries by using the secondgeneration SPIDER-graft might further reduce the risk of SCI. In this study, quantitative assessment of spinal cord perfusion showed that spinal cord perfusion was significantly increased after reattachment of lumbar arteries during secondgeneration SPIDER-graft compared with both study groups without reattachment. Even first-generation SPIDER-graft 


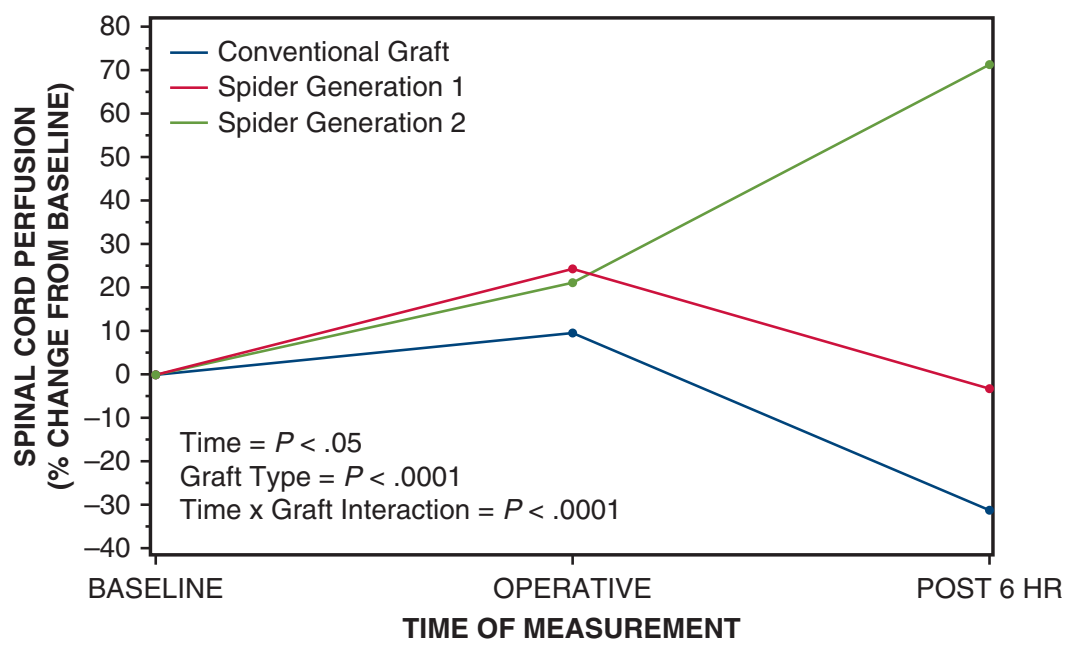

FIGURE 3. Spinal cord perfusion assessed by FMs calculated by multilevel models illustrated as percent change from baseline. During conventional graft (control) spinal cord perfusion decreased compared with baseline values, whereas first-generation SPIDER-graft showed a transient increase during implantation to decrease to baseline values after 6 hours observation. During second-generation SPIDER-graft with reimplantation of lumbar arteries as loop-graft spinal cord, perfusion showed significant increase at 6 hours compared with baseline and the other study groups. Main effects of treatment group and time are statistically significant. Time-by-treatment interaction is also highly statistically significant, indicating that the rate of change over time is different between the graft designs. Statistics are from multilevel random-intercept models.

showed stable spinal cord perfusion values compared with baseline values, whereas spinal cord perfusion decreased in the control group during 6 hours observation. This might be due to ischemia-reperfusion-induced hypotension in the control group with significantly longer ischemic time compared with SPIDER-graft.

However, anatomy of the porcine spinal blood supply is markedly different than in humans, because the segmental thoracic and lumbar arteries are relatively small and often originate as a single branch from the aorta. ${ }^{16}$ Despite the knowledge and identification of main risk factors for SCI associated with open and endovascular aortic repair, the hybrid approach has not been completely successful in eliminating the risk. ${ }^{17}$ Although the aneurysm extent and rupture presentation are not modifiable risk factors, however, intraoperative clamping time, hypotension, and patent lumbar and intercostal artery sacrifice are factors that can be influenced.

The SPIDER-graft offers many potentially preventive strategies concerning SCI. Technical success of graft deployment was achieved for both first- and secondgeneration SPIDER-graft, but the new design of the second-generation graft appeared more favorable.

\section{Study Limitations}

Despite recent advances in perioperative management and surgical techniques, complication rates after OAR remain high. ${ }^{18-20}$ Hybrid aortic repair with extra-anatomic bypass followed by TEVAR showed less favorable results regarding mortality and morbidity compared with standard open thoracoabdominal repair. ${ }^{17,21,22}$

\section{CONCLUSIONS}

The SPIDER-graft had shorter crossclamping and ischemic times compared with OAR in this experimental porcine setting. The proof of concept of passive shunting by retrograde visceral perfusion was confirmed, obviating the need for ECC. Therefore, ECC-related hypotension, postoperative complement-induced edema formation, risk of bleeding, and need for blood products can be reduced by using SPIDER-graft while maintaining patent spinal cord perfusion by reattachment of lumbar arteries.

\section{Webcast}

You can watch a Webcast of this AATS meeting presentation by going to: https://aats.blob.core.windows. net/media/18May01/28ABC\%201.Emerg\%20Tech\%20 Cardiac/S76_7_webcast_081950273.mp4.

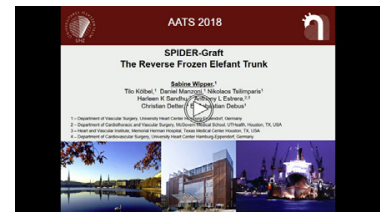

\section{Conflict of Interest Statement}

S.W.: research grant covering animal costs, SPIDER-graft prosthesis, and travel grant. T.K.: research grant, travel grant, patents pending. D.M.: research grant covering animal costs and SPIDER-graft prosthesis. E.S.D.: research grant covering animal costs, SPIDER-graft prosthesis, and travel grant. All other authors have nothing to disclose with regard to commercial support. 
The authors acknowledge the skillful assistance of Detlef Russ during FM analysis at the Instutut für Lasertechnologie in der Medizin-und Messtechnik, Ulm, Rickmer Uhlig for participating in the animal experiments during his doctoral thesis, and Anna Kammal and Michael Kammal for their support in performing the postmortem CT angiographies.

\section{References}

1. Coselli JS, LeMaire SA, Weldon SA. Extent II repair of thoracoabdominal aortic aneurysm secondary to chronic dissection. Ann Cardiothorac Surg. 2012;1:394-7.

2. LeMaire SA, Price MD, Green SY, Zarda S, Coselli JS. Results of open thoracoabdominal aortic aneurysm repair. Ann Cardiothorac Surg. 2012;1:286-92.

3. Girardi LN, Rabotnikov Y, Avgerinos DV. Preoperative percutaneous coronary intervention in patients undergoing open thoracoabdominal and descending thoracic aneurysm repair. J Thorac Cardiovasc Surg. 2014;147:163-8.

4. Estrera AL, Jan A, Sandhu H, Shalhub S, Medina-Castro M, Nguyen TC, et al. Outcomes of open repair for chronic descending thoracic aortic dissection. Ann Thorac Surg. 2015;99:786-94.

5. Piazza M, Ricotta JJ. Open surgical repair of thoracoabdominal aortic aneurysms. Ann Vasc Surg. 2012;26:600-5.

6. Wynn MM, Acher C, Marks E, Engelbert T, Acher CW. Postoperative renal failure in thoracoabdominal aortic aneurysm repair with simple cross-clamp technique and $4^{\circ} \mathrm{C}$ renal perfusion. $J$ Vasc Surg. 2015;61:611-22.

7. Nathan DP, Brinster CJ, Woo EY, Carpenter JP, Fairman RM, Jackson BM. Predictors of early and late mortality following open extent IV thoracoabdominal aortic aneurysm repair in a large contemporary single-center experience. J Vasc Surg. 2011;53:299-306

8. Wong DR, Parenti JL, Green SY, Chowdhary V, Liao JM, Zarda S, et al. Open repair of thoracoabdominal aortic aneurysm in the modern surgical era: contemporary outcomes in 509 patients. J Am Coll Surg. 2011;212:569-79.

9. Debus ES, Koelbel T, Wipper S, Diener H, Reiter B, Detter C, et al. Reversed frozen elephant trunk technique to treat a type II thoracoabdominal aortic aneurysm. J Endovasc Ther. 2017;24:277-80.

10. Debus ES, Kölbel T, Duprée A, Daum G, Sandhu HL, Manzoni D, et al. Feasibility study of a novel thoraco-abdominal aortic hybrid device (SPIDER-graft) in a translational pig model. Eur J Vasc Endovasc Surg. 2018;55:196-205.

11. Wipper S, Lohrenz C, Peymann K, Russ D, Kersten JF, Carpenter SW, et al. Hemodynamic impact of transseptal access to the ascending aorta in a porcine model. J Endovasc Ther. 2012;19:679-88.

12. Detter C, Wipper S, Russ D, Iffland A, Burdorf L, Thein E, et al. Fluorescent cardiac imaging: a novel intraoperative method for quantitative assessment of myocardial perfusion during graded coronary artery stenosis. Circulation. 2007; 116:1007-14

13. Wipper S, Reiter B, Russ D, Hahnel F, Kersten JF, Kölbel T, et al. Distinction of non-ischemia inducing versus ischemia inducing coronary stenosis by fluorescent cardiac imaging. Int J Cardiovasc Imaging. 2016;32:363-71.

14. Rudolph TK, Wipper S, Reiter B, Rudolph V, Coym A, Detter C, et al. Myeloperoxidase deficiency preserves vasomotor function in humans. Eur Heart J. 2012;33:1625-34.

15. Glenny RW, Bernard S, Brinkley M. Validation of fluorescent-labeled microspheres for measurement of regional organ perfusion. J Appl Physiol. 1993;74:2585-97.

16. Strauch JT, Lauten A, Zhang N, Wahlers T, Griepp RB. Anatomy of spinal cord blood supply in the pig. Ann Thorac Surg. 2007;83:2130-4.

17. Chiesa R, Tshomba Y, Melissano G, Marone EM, Bertoglio L, Setacci F, et al. Hybrid approach to thoracoabdominal aortic aneurysms in patients with prior aortic surgery. J Vasc Surg. 2007;45:1128-35.

18. Bensley RP, Curran T, Hurks R, Lo RC, Wyers MC, Hamdan AD, et al. Open repair of intact thoracoabdominal aortic aneurysms in the American College of Surgeons national surgical quality improvement program. J Vasc Surg. 2013;58:894-900.

19. Kouchoukos NT, Kulik A, Castner CF. Outcomes after thoracoabdominal aortic aneurysm repair using hypothermic circulatory arrest. J Thorac Cardiovasc Surg. 2013;145:S139-41

20. Lancaster RT, Conrad MF, Patel VI, Cambria MR, Ergul EA, Cambria RP. Further experience with distal aortic perfusion and motor-evoked potential monitoring in the management of extent I-III thoracoabdominal aortic aneurysms. J Vasc Surg. 2013;58:283-90.

21. Rosset E, Ben Ahmed S, Galvaing G, Favre JP, Sessa C, Lermusiaux P, et al. Editor's choice - hybrid treatment of thoracic, thoracoabdominal, and abdominal aortic aneurysms: a multicenter retrospective study. Eur J Vasc Endovasc Surg. 2014;47:470-8.
22. Hughes GC, Andersen ND, Hanna JM, McCann RL. Thoracoabdominal aortic aneurysm: hybrid repair outcomes. Ann Cardiothorac Surg. 2012;1:311-9.

Key Words: hybrid repair, thoracoabdominal aorta, TAAA, experimental study, stentgraft

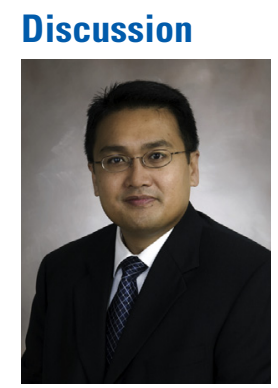

Dr Anthony L. Estrera (Houston, Tex). Nice job, Sabine. I have nothing to disclose regarding this. In thinking about this you might ask, why would we ever do this operation? One is using a frozen elephant trunk hybrid stent graft and implanting this in a reversed fashion, then bypassing the visceral vessels to address the extensive TAAA. But if you really think about it, Dr Coselli is going to present an article at this annual American Association for Thoracic Surgery meeting on open repair extent II TAAA repair and reporting a paraplegia rate of $14 \%$. So the fact remains that extent II TAAA is a big operation. I do believe the frozen elephant trunk is a nice procedure. I think once we get access to these grafts in the United States, at least for me, I will be using this for all my elephant trunk procedures, because it helps reduce the magnitude of the extent II repair that may eventually be required.

I look forward to Sabine's work in the future; she has done a really good job on this project. And whether it has huge applicability in the future, I really don't know, but I do think we need to try to reduce the overall magnitude of the procedure and reduce the stress on the patient, because when Joseph Coselli reports a $14 \%$ paraplegia rate, the extent II thoracoabdominal aneurysm is still an issue.

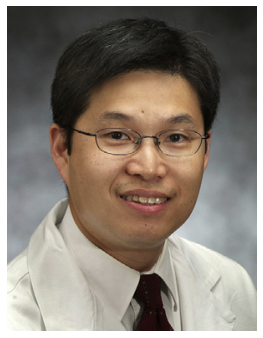

Dr Wilson Szeto (Philadelphia, Pa). The Type IIs are the tough ones, and I am going to have to throw this out there in the room. Where is this going to sit in the ever increasing introduction of completely endobranched grafts? Where is this going to sit? I think it's going to be complementary, not competitive. But what do you see 5, 6 years from now as we have more experience with complete endothoracoabdominal branched devices versus this?

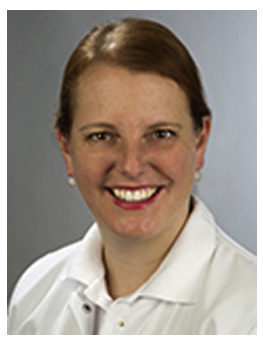

Dr Sabine Wipper (Hamburg, Germany). The aim of this graft is, first, to be used in patients with connective tissue disease where we usually create at the moment a landing zone on the distal aorta. The patients usually have already a frozen elephant trunk, and it will be easy to connect both. We have 2 patients on the waiting list actually who have connective 
tissue disease with an existing graft and they have also a stent graft until the celiac trunk, and this will make the approach easier. And in combination, we have the ability to reduce SCI. Although we have multiple potentials, we might do a little thoracotomy and reattach the T8 to T12. So that might be an advantage.

Dr Szeto. A technical question. The proximal portion of this device, what was the diameter?

Dr Wipper. In the pigs, we had $15 \mathrm{~cm}$, but we will create different lengths, because we need different lengths concerning the length of the thoracic outlet.

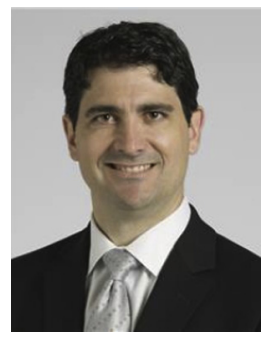

Dr Eric Roselli (Cleveland, Ohio). Great work, nice to see it again. You did a great job presenting this in New York recently as well. My question is related to the validity of the model you have been using. These are pigs with normal aortas, and eventually we are expecting to use this endograft device to essentially do an anastomosis in a diseased human aorta. Have you done additional testing to look at things like pull-out strength and seal under different kinds of conditions that mimic the diseased state to get a sense of whether the radial force of the stent graft is truly enough to get fixation and seal in that more proximal aorta?

Dr Wipper. Yes, we did, and we experienced during second-generation SPIDER-graft that it was not enough, so we modified the ring stent and we have a new stent graft with modified orientation of the ring stents for the third generation. The company actually tests the longitudinal stability of the graft. In our animal study in healthy pigs, we had no migration of the stent-graft. To support this, we increased the blood pressure to a systolic blood pressure above $180 \mathrm{~mm} \mathrm{Hg}$ and observed them. Final CT scan confirmed safe fixation. But in humans with aneurysmatic aortic disease, we recommend in addition to suture the collar to the native aorta. This further prevents distal migration. 